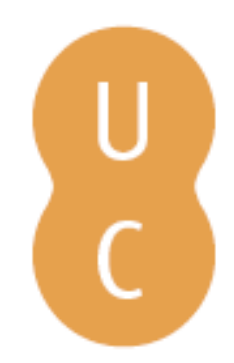

\title{
pommalina
}

\section{Practical challenges in determining periodic maintenance intervals on the Norwegian Continental Shelf (NCS): Some expert views and opinions}

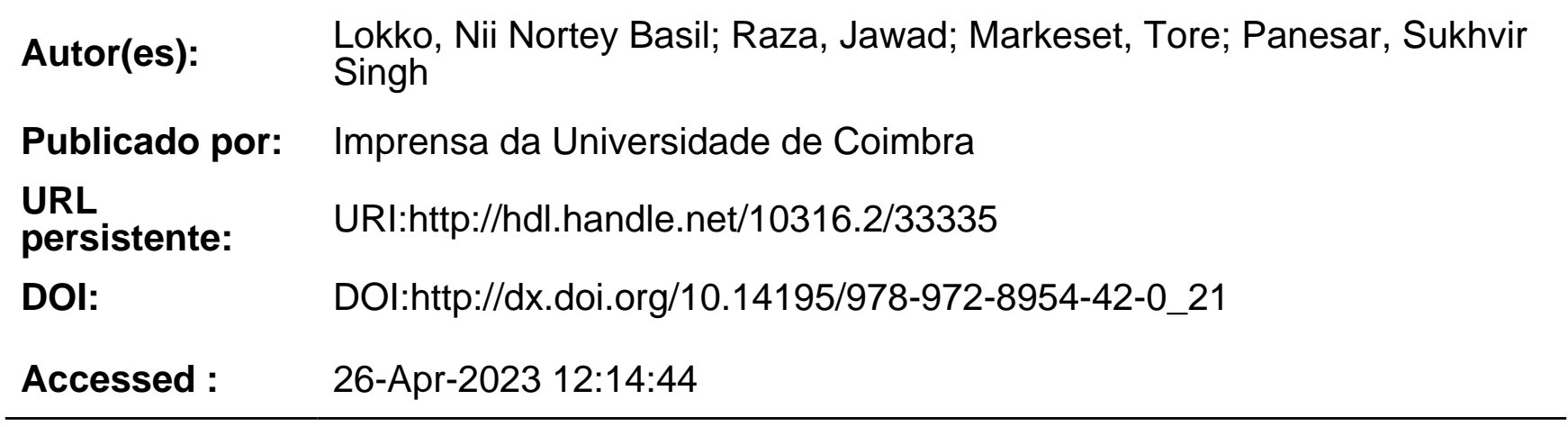

A navegação consulta e descarregamento dos títulos inseridos nas Bibliotecas Digitais UC Digitalis, UC Pombalina e UC Impactum, pressupõem a aceitação plena e sem reservas dos Termos e Condições de Uso destas Bibliotecas Digitais, disponíveis em https://digitalis.uc.pt/pt-pt/termos.

Conforme exposto nos referidos Termos e Condições de Uso, o descarregamento de títulos de acesso restrito requer uma licença válida de autorização devendo o utilizador aceder ao(s) documento(s) a partir de um endereço de IP da instituição detentora da supramencionada licença.

Ao utilizador é apenas permitido o descarregamento para uso pessoal, pelo que o emprego do(s) título(s) descarregado(s) para outro fim, designadamente comercial, carece de autorização do respetivo autor ou editor da obra.

Na medida em que todas as obras da UC Digitalis se encontram protegidas pelo Código do Direito de Autor e Direitos Conexos e demais legislação aplicável, toda a cópia, parcial ou total, deste documento, nos casos em que é legalmente admitida, deverá conter ou fazer-se acompanhar por este aviso.

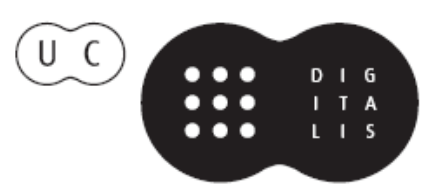




\title{
Practical challenges in determining periodic maintenance intervals on the Norwegian Continental Shelf (NCS): Some expert views and opinions
}

\author{
Nii Nortey Basil Lokko'; Jawad Raza ${ }^{2}$; Tore Markeset ${ }^{1}$; Sukhvir Singh Panesar ${ }^{1}$ \\ 1,2 nii,nortey.lokko@uis.no; 1,2 jawad.raza@,applysorco.no; ${ }^{1}$ tore.markeset@uis.no; ${ }^{1}$ sukpane@yahoo.com \\ ${ }^{1}$ University of Stavanger, N4012 Stavanger, Norway \\ ${ }^{2}$ Apply Sørco AS, N4012 Stavanger, Norway
}

\begin{abstract}
Maintenance is one of the key success factors for ensuring safe and reliable operations on the Norwegian continental shelf (NCS). Periodic maintenance is still a large part of the maintenance portfolio even if the ambition is to shift towards dynamic strategies. Therefore, one can conclude that, currently, the availability of offshore production facilities on the NCS is significantly influenced by maintenance programs that are based on predetermined periodic maintenance tasks.
\end{abstract}

This paper reviews current practices and experiences for determining intervals for performing maintenance tasks. The mapping is performed by comparing theoretical and practical industrial approaches to determine the preventive maintenance task intervals. The paper highlights some practical issues and challenges that maintenance engineers face in the determination of task frequencies/intervals on the NCS.

The study shows that the biggest challenge for the maintenance engineers is to determine the "optimal interval" for the maintenance tasks. A frequent task will increase the maintenance costs, whilst an extended interval could increase the risks related to unexpected failures. The maintenance engineers use their engineering judgment by combining manufacturer recommendations, regulatory requirements and operational needs to determine optimal intervals. The NCS, however, needs more dynamic maintenance strategies that are data driven but without the inhibiting computational and practical issues currently available in existing theoretical mathematical models.

\section{Keywords-Preventive maintenance, maintenance interval}

\section{INTRODUCTION AND BACKGROUND}

Predetermined periodic maintenance is a part of the broader concept of Preventive Maintenance (PM). Hence, drawing from standards such as EN 13306 [1], ISO 14224 [2], NORSOK Z-008 [3] and other literature, predetermined periodic maintenance may be defined as planned maintenance carried out on the basis of regular time intervals intended to reduce the probability of failure or the degradation of the function of an item ${ }^{1}$.

According to Mobley et al [4], predetermined periodic maintenance is based on the assumption that equipment will degrade and fail within a time frame (operational hours/calendar) that is typical of its particular classification. This assumption is accepted to be generally true. Experience, on the other hand, suggests that degradation and failure can occur outside this typical time frame, even for similarly classified equipment. Nonetheless, it is this assumption that forms the basis of why predetermined periodic maintenance is mathematically rooted in the concepts of statistics and probability. Three interpretations of probability are acknowledged in probability theory: classical, relativefrequency and subjective interpretations [5]. The relativefrequency interpretation of probability satisfies the scientific requirements of objectivity and repeatability. It also provides a probability interpretation that is closest to the assumption underlying predetermined periodic maintenance. This interpretation, understandably, forms the principal element of several models used for the determination of predetermined periodic maintenance intervals.

Maintenance activities and intervals are defined in a typical PM program. However, on the Norwegian continental shelf (NCS), developing a PM program also includes preparing PM task routines, specifying the requirement for spare parts, estimating the duration for executing each maintenance activity and assigning a discipline responsible for each maintenance activity. The study presented in the ensuing section will therefore be limited to determining the interval of maintenance tasks for a PM program on the NCS.

In this paper, we briefly review how predetermined periodic maintenance intervals are theoretically determined and compare these general concepts with practices on the NCS. We present two perspective views of the process of determining maintenance intervals on the NCS and also discuss some challenges in the PM program determination. The paper is primarily based on interviews with maintenance experts. Expert opinion from practicing engineers was sought in establishing the role that predetermined periodic maintenance plays in ensuring oil and gas $(\mathrm{O} \& \mathrm{G})$ asset availability. A brief literature survey was also undertaken, discussing general theoretical approaches to establishing predetermined periodic maintenance programs.

\footnotetext{
${ }^{1}$ An item is defined as, "any part, component, device, or an assembly of parts that is normally the lowest level in the hierarchy during maintenance" [3]
} 


\section{THEORETICAL ESTIMATION OF PREDETERMINED PERIODIC MAINTENANCE INTERVALS}

The determination of periodic maintenance intervals begins by finding the appropriate probability distribution to describe the equipment failure process. Establishing the probabilistic nature of the underlying failure process may be attained either by a parametric method or a non-parametric/empirical method [5]. Whichever method is chosen, a statistical analysis of equipment failure data is required. Most often though, real-life failure data fits the Weibull distribution [5] [6] [7]. The Weibull distribution is therefore considered the most appropriate probability distribution for inspection and preventive maintenance activities because of its possible application to a wide range of scenarios and its ability to approximate several other distributions.

The failure rate (number of failures per unit of time), often used to derive the statistical parameter known as he mean time to failure (MTTF), is a key reliability measure in the determination of periodic maintenance intervals. In addition to the failure rate, a description of the failure process requires the determination of the following: 1) the probability density function of the time to failure, 2) the cumulative density function, 3) the reliability function; and 4) the hazard function.

Once the probabilistic nature of the failure process has been defined, and the relevant parameters determined, any of the numerous theoretical models might be used to determine the most appropriate interval. These models suggest an optimal time for replacements [8] [9], inspections [6] [10] [11] [12] [13], and overhauls [14] [15] [16] [17]. Complex analysis techniques, such as Markov chains, Bayesian modeling, simulations, fuzzy logic, expert systems and genetic algorithms, form the basis for some of these models. Hence, they require a considerable amount of time, research and analysis to define a specific scenario. Furthermore, the analyst requires competence and skills in applying the methods and in assessing the assumptions to be applied to the system in question.

Models are developed with a specific target objective in mind. Either minimizing maintenance cost, reducing downtime, enhancing reliability, availability, maintainability or a combination of some or all of these objectives has been discussed and modeled in research works. The determination of periodic maintenance intervals thus transcends the intrinsic failure characteristics of the equipment. Applications of such models thus require the collection and storage of detailed information (both qualitative and quantitative). Such detailed information includes equipment failure, operation regimes, maintenance actions, modifications and related costs [18]. The intervals determined via these models are, therefore, a translation of specific corporate/business objectives and operating strategies.

\section{THE NORSOK GUIDELINES FOR PM INTERVAL DETERMINATION}

The maintenance management process defined in NORSOK Z-008 [3] also acknowledges the derived theoretical influence of specific corporate/business objectives and operating strategies on PM intervals and programs. Hence, the maintenance programs on the NCS are developed on the basis of the goals and requirements specific to each O\&G company but with a focus on:

- Reducing risks, increasing production and lowering cost

- Compliance with applicable regulatory requirements

- The technical condition of the facility (in particular the performance of safety systems and critical processes)

- Improvement of the overall maintenance process.

Consequence classification is the main foundation for the development of PM programs on the NCS. The classification is an analysis that determines the effects of potential equipment functional failures on HSE, production and costs by breaking down all the installation's functions into main and sub functions. Once the groupings and the classifications have been completed, maintenance activities and intervals are then determined.

For equipment classified as safety critical, testing intervals are determined on the basis of the performance requirements of their safety functions (OLF 070 [19] or IEC 61508). For nonsafety critical equipment, one of the following options is employed:

- Referring to standardized/ generalized strategies/ concepts. These standardized concepts are developed by performing detailed reliability-centered maintenance (RCM) analysis on equipment and documenting results such that they can be used for similar equipment of the same classification. Company-specific operational and maintenance experiences (best practices) as regards specific equipment are also used to enhance the RCM analysis results. Thus, within the framework of NORSOK Z-008, generalized strategies/concepts on the NCS are regarded as an efficient mode of capturing standardized company knowledge. The use of generalized maintenance strategies/concepts is considered an indirect RCM analysis on the specific equipment being examined.

- Performing detailed RCM analysis and risk-based inspection (RBI) methods to determine the specific maintenance activities, intervals and plans for execution for the equipment/system.

- $\quad$ Referring to original equipment manufacturers' (OEM) recommendations on maintaining the equipment/system.

- Deciding to run the equipment/system to failure.

Performing a cost/benefit analysis is one of the recommended steps to determine cost-effective maintenance activities for selected equipment. For low consequence class assets, however, an interpretation of the guidelines suggests that risk analysis and/or cost/benefit analysis may not always be a necessary activity. 


\section{THE EXISTING PRACTICAL APPROACH TO DETERMINING PM INTERVALS ON THE NCS}

On the NCS, there is a practical approach for identifying and developing an effective PM program, which mainly involves the consideration (among others) of:

- Regulatory and company requirements

- Company-specific best practices

- Generalized maintenance strategies/concepts
- Original equipment manufacturers' recommendations, and

- National and international standards and guidelines

Statutory regulations/requirements, as well as national (NORSOK) and international standards (ISO, IEC), are considered in the PM interval and activity determination process. Where there is a clearly defined statutory requirement, it supersedes any practice, concept, standard, recommendation or guideline.

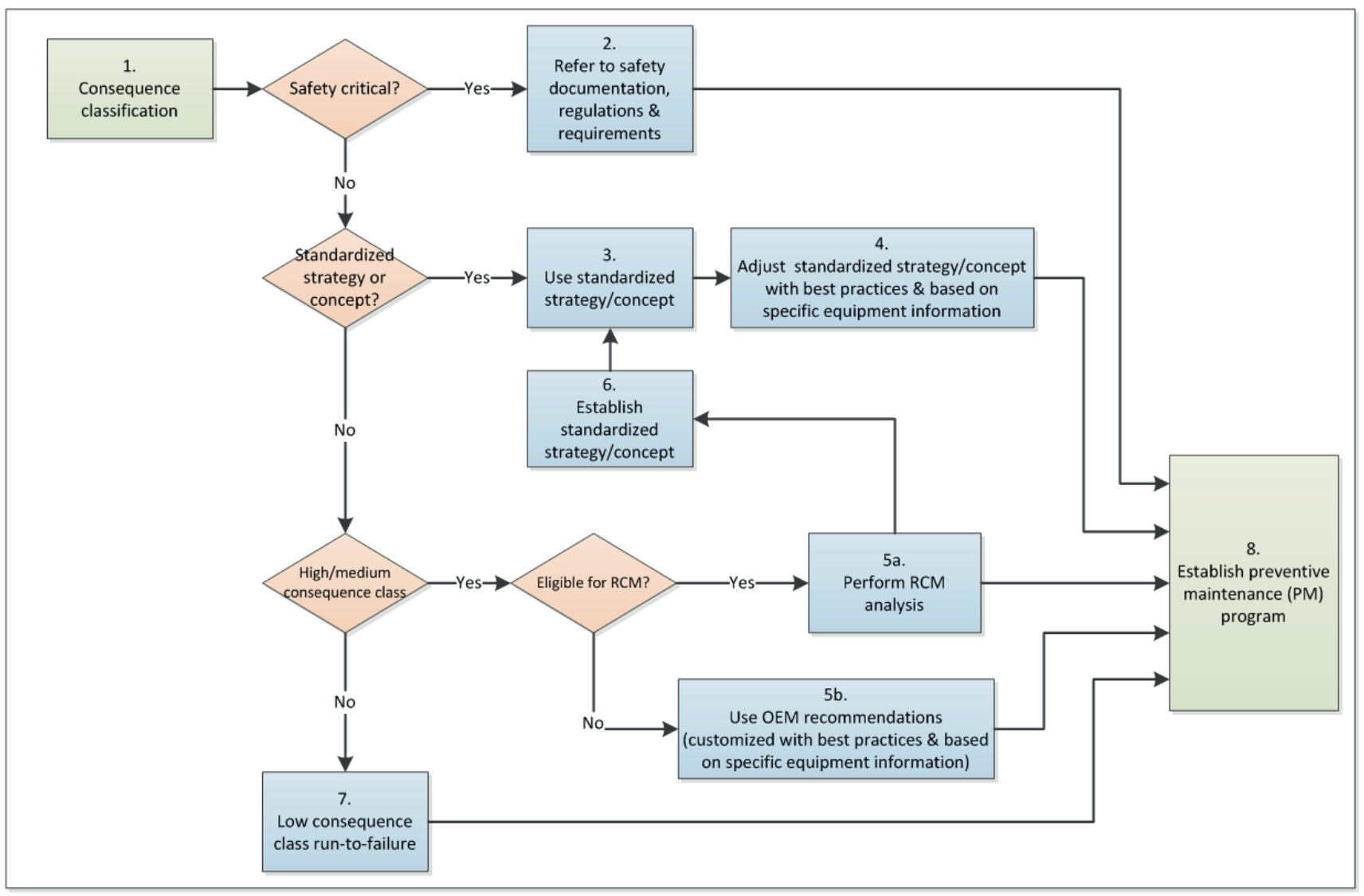

Fig. 1. Establishing a maintenance program: process description by Company A

Figure 1, therefore, captures an example of the process of establishing a maintenance program (as interpreted by a leading maintenance service provider on the NCS).

The work process in Figure 1 depicts a typical, simplified and relatively accurate interpretation of the maintenance guidelines on the $\mathrm{NCS}^{2}$. Keeping in mind that the standardized maintenance strategies/concepts are defined for a specific/generic group of items, the above process suggests that the time-consuming and capital-intensive RCM analysis will only be employed in certain special scenarios (refer to the

${ }^{2}$ This, however, is from the perspective of maintenance service providers (i.e. maintenance engineers who are often contracted by the operators to assist in developing a maintenance program). section on "some identified challenges in determining the optimum maintenance interval on the NCS").

Best practices and standardized concepts (if available) are therefore the primary sources of decision-making information with regard to PM interval determination on the NCS. According to some practicing maintenance engineers, these practices and concepts are significantly influenced by several years of personnel experience on the operation and maintenance of similar types of equipment. Inherent in these experiences are the corporate/business goals and objectives that govern all operations/activities. The generalized maintenance strategies/concepts can be considered as a maintenance representation of an operating company's corporate strategies. 
The OEM recommendation is also a major contributory factor in the PM interval determination process. Engineers on the NCS believe that, due to the constraints of contractual agreements pertaining to aftersales services, the OEM recommendations are increasingly becoming a major source for determining PM intervals. Opinions suggest that since OEMs prefer to avoid failures during the equipment warranty period, they often recommend conservative maintenance programs. Such programs, if not adjusted after the warranty period, can lead to a continued reliance on maintenance programs that may lead to more downtime and more spares in storage than necessary or simply over maintenance. This current trend may also have been compounded by the development and use of innovative technologies by operators on the NCS, for which little or no experience is available. This lack of experience (with regard to innovative technologies) has led to conservative and costly maintenance programs where too much maintenance is being done too often.

Figure 2 depicts a six-step process of establishing a maintenance program that is suggestive of a more operational interpretation of the NORSOK guidelines.

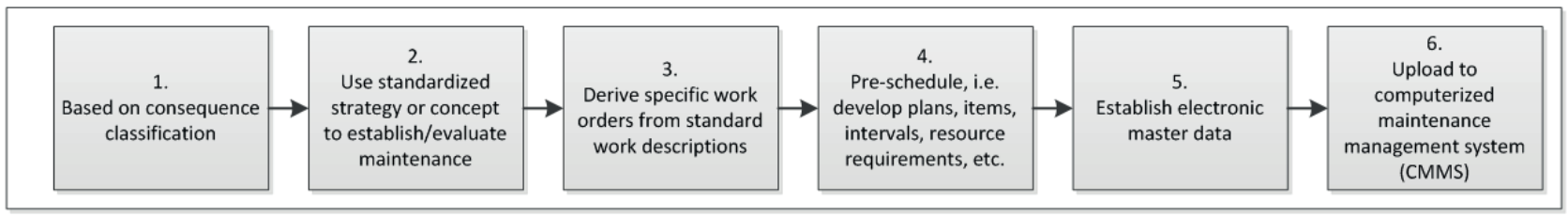

Fig. 2. Maintenance program development process by Company B.

The work process in Figure 2 is a view from the operating company's perspective. The operators themselves appear to be satisfied with being reliant on standardized maintenance strategies/concepts when available and wherever applicable. The figure seems to indicate that $O \& G$ operators consider plans for execution as part of the PM program. This is in contrast to the service providers' interpretation, which generally does not include such plans. Despite this contrast, good collaboration exists between maintenance service providers and O\&G operators. Both, however, seem to agree that, even when generalized maintenance strategies/concepts are available, the establishing of maintenance intervals and activities is a major issue to contend with on the NCS.

\section{SOME IDENTIFIED CHALLENGES IN DETERMINING THE OPTIMUM MAINTENANCE INTERVAL ON THE NCS}

\section{A. The challenge of using existing theoretical models}

Basic definitions for equipment reliability make reference to the probability of performing intended function(s) under certain prevailing conditions, and over a predefined time period [20]. Since predetermined periodic maintenance is a significant part of the PM on the NCS (according to several maintenance engineers), an equally significant part of improving reliability on the NCS can be suggested as a function of predetermined periodic maintenance. It is on this basis that theoretical approaches to establishing this time interval may be considered appropriate for establishing initial PM programs on the NCS. However, a major difficulty with these theoretical models is that not all the input (e.g. equipment failure history data, downtime and cost data) may be available to the maintenance engineer, especially in cases where the installations are new.

Some maintenance engineers on the NCS are of the opinion that, even when all such quantitative (and to some extent qualitative) data is available (as may be the case for some existing old installations), the reliability of the data itself maybe an inhibiting issue. These engineers also suggest that it is quite impractical to even consider the utilization of some of these models when they are faced with the task of determining the PM intervals for several thousands of tagged items. There are too many tags to be assessed individually, even if sufficient reliable data is made available. It would simply be computationally strenuous and time-consuming to perform such an assessment using most of the existing models.

\section{B. The challenge of using best practices and generalized maintenance strategies/concepts}

The assumption underlying theoretical mathematical models (i.e. equipment will degrade and fail within a fixed time frame typical of its particular classification) is also the basis for developing generalized maintenance strategies/concepts and using best practices. Consequently, the inherent limitation within mathematical models (i.e. the underlying assumption could be false), is also a limitation for relying on company best practices and generalized maintenance strategies/concepts for establishing PM programs.

The general nature of best practices and generalized maintenance strategies/concepts allows for some level of subjectivity if they are to be employed effectively for specific operating scenarios. Since generalized maintenance strategies/concepts are specifically defined for a group of equipment operating under similar conditions (i.e. particular classification), the judgment on similarity is often dependent on the responsible engineer(s). The adjustments that would be necessary in instances of deviations are also influenced by personal practical experiences and personal risk tolerance levels. An incorrect judgment (for example because of the responsible engineer's higher or lower personal risk tolerance) would likely result in costly, inefficient maintenance.

It was also suggested that, in the absence of generalized maintenance strategies/concepts (and specific company best practices), original equipment manufacturer (OEM) recommendations and/or other detailed reliability analyses such as RCM may be required. This, however, is dependent on the consequence classification groupings. Slight modifications to the OEM recommended PM activities with respect to 
functional and operational parameters would, in some cases, be sufficient. The available reliability standards [2] and databases (OREDA) which can provide useful information about critical failure modes and mechanisms etc. may be used for such adjustments. However, in principle OEM maintenance recommendations are either the specific best practices of that particular OEM or the generalized maintenance strategy/concept of the OEM for similar equipment types. Hence, the OEM recommendations may be limited in the same manner (if not more so) as earlier discussed in this section.

\section{The challenge of applying RCM analysis}

The study also indicated that there is an increasing request for RCM analysis on critical items on the NCS. Many engineers are in favor of performing RCM but are also quick to point to the time and resource (human and capital) intensive nature of the analysis as its major impediment. One engineer described an example where it took two fully dedicated engineers and a number of discipline experts more than three weeks to complete a full failure mode, effects and criticality analysis (FMECA). The FMECA was on two electro-plates (with no moving parts) for a subsea module. The engineer then emphasized that a complete FMECA is an integral part of any $\mathrm{RCM}$ analysis.

Some experts are of the view that another major challenge with RCM is that only a limited number of people actually who understand the process [21]. The opinion is that RCM takes time and requires an experienced facilitator who understands real failure modes. A thorough understanding of how functional failure is interconnected with how items work together, as well as the available actions and techniques to ensure equipment reliability, is a scarce expertise.

In principle, therefore, all items can benefit from RCM analysis. However, time and resource limitations indicate that priorities need to be defined. Hence, a detailed RCM analysis is only undertaken for some selected equipment.

\section{FURTHER DISCUSSIONS}

The discussion thus far indicates that the practical approach employed on the NCS relies largely on qualitative data/information (best practices, generalized maintenance strategies/concepts, OEM recommendations and standards/regulations) as against the quantitative data that is required for the existing mathematical models. Without the right experience and/or expertise, the subjectivity involved in interpreting (or deducing from) qualitative data can result in the development of PM programs with intervals that are ineffective. The challenges identified with regard to the use of theoretical mathematical models may have influenced the development of this qualitative approach on the NCS. There is, however, the need for the use of more quantitative data on the NCS.

Recent developments in technology have improved the ability to capture and store precise and accurate equipment data. Continuous technological advancement is thus providing the industry with innovative techniques with which to analyze the captured equipment data, and transform such data into decision-making information. Integrated Operations $(\mathrm{IO})^{3}$ is also a current operating regime on the NCS that provides the kind of collaborative environment that fosters the implementation of more dynamic strategies such as predictive maintenance. The challenge, however, is to develop innovative tools that readily and cost-effectively provide decision support regarding the health and condition of equipment (most preferably in real time). Such tools will provide the opportunity to relate the maintenance activities to condition rather than over-reliance on existing predetermined activities. Also, there is the ever-deepening challenge of developing competences that can effectively use any such tools and positively exploit the expertise made available in collaborative environments (such as IO).

The availability level of offshore assets is constantly under pressure. Expert opinion suggests that the know-how and practical experience required in establishing and continuously improving effective PM programs is wearing thin. Offshore operating regimes continue to increase in complexity (exemplified by recent Arctic operations). Consequently, despite the general feeling that predetermined periodic maintenance currently dominates offshore maintenance activities, this study expects predictive and dynamic maintenance strategies (which are data driven) to play a more significant role in improving the level of equipment availability in the near future.

\section{CONCLUDING REMARKS}

In summary, we have (on one hand) pure theoretical models based on reliability theory, whose applicability is somewhat in doubt by some maintenance engineers on the NCS. Some of these theoretical models lead to PM intervals that often result in either too little or too much maintenance. In addition, each of these models also has its related unwanted cost effects. On the other hand, we have a practical approach that is subjective, but which has been applied extensively for the determination of PM intervals and activities on the NCS. The overriding feature regarding the determination of task frequencies/intervals on the NCS is the art of combining equipment manufacturer recommendations, operating company's best practices, and the Norwegian O\&G regulatory framework with long-term operating experiences. Practical experiences, however, suggest that this practical approach often also results in either too little or too much maintenance.

The current approaches to determining PM intervals and activities on the NCS contribute to ensuring the availability and reliability of offshore equipment. There is, however, more room for improvement, especially in the area of maintenance effectiveness and efficiency with respect to the use of qualitative equipment data. There is a need for more dynamic maintenance strategies that are data driven but without the inhibiting computational and practical issues currently available in the existing theoretical mathematical models (as previously discussed). These dynamic strategies must be

3 IO is an initiative from the Norwegian Oil Industry Association (OLF), which emphasizes the need to use "ubiquitous real time data, collaborative techniques and multiple expertise across disciplines, organizations and geographical locations" to aid in taking smarter decisions [22]. 
sufficient to encapsulate those failures that are typical of specifically classified equipment types and those failures that make current maintenance strategies occasionally seem inadequate. Hence, these dynamic strategies must lay more emphasis on establishing the current condition of equipment (under prevailing operating and environmental circumstances) and incorporating methods for reassessment and adjustment of the maintenance strategy over time.

The need to pursue more dynamic concepts to optimize periodic maintenance on the NCS is widespread.

\section{ACKNOWLEDGMENT}

We would like to acknowledge all asset managers and maintenance engineers from the NCS who contributed to this study.

\section{REFERENCES}

[1] EN 13306, (2010), Maintenance - Maintenance terminology

[2] ISO 14224, (2006), Petroleum, petrochemical and natural gas industries - Collection and exchange of reliability and maintenance data for equipment

[3] NORSOK Z-008, (2011), Risk based maintenance and consequence classification

[4] Mobley, R.K., Higgins, L.R. and Wikoff, D.J., (2008), Maintenance Engineering Handbook, McGraw-Hill, New York

[5] Verma, A.K., Ajit, S. and Karanki, D.R., (2010a), Basic reliability mathematics, in: Reliability and Safety Engineering, Springer Series in Reliability Engineering. Springer London, pp. 15-70

[6] Hariga, M.A., (1996), A maintenance inspection model for a single machine with general failure distribution, Microelectronics Reliability: issue 36, pp. 353-358

[7] Verma, A.K., Ajit, S. and Karanki, D.R., (2010b), Mechanical reliability, in: Reliability and Safety Engineering, Springer Series in Reliability Engineering. Springer London, pp. 229-266

[8] Nakagawa, T. and Mizutani, S., (2009), A summary of maintenance policies for a finite interval, Reliability Engineering and Systems Safety: issue 94, pp. 89-96
[9] Young Yun, W. and Nakagawa, T., (2010), Replacement and inspection policies for products with random life cycle, Reliability Engineering and Systems Safety: issue 95, pp. 161-165

[10] Nakagawa, T. and Osaki, S., (1974), Optimum preventive maintenance policies maximizing the mean time to the first system failure for a twounit standby redundant system, Journal of Optimization Theory and Applications: issue 14, pp. 115-129

[11] Nakagawa, T., (1980), Replacement models with inspection and preventive maintenance, Microelectronics Reliability: issue 20, pp. 427433

[12] Lu, X., Wang, W., Yang, H., Zuo, M.J. and Zhou, D., (2012), Optimizing the periodic inspection interval for a 1-out-of-2 cold standby system using the delay-time concept, Quality and Reliability Engineering International: issue 28, pp. 648-662

[13] Wang, C.H. and Sheu, S.H., (2003), Determining the optimal production-maintenance policy with inspection errors: using a Markov chain, Computers \& Operations Research: issue 30, pp. 1-17

[14] Louit, D., Pascual, R. and Banjevic, D., (2009), Optimal interval for major maintenance actions in electricity distribution networks, International Journal of Electrical and Power Energy Systems: issue 31, pp. 396-401

[15] Mathew, J. and Rajendran, C., (1993), Scheduling of maintenance activities in a sugar industry using simulation, Computers in Industry: issue 21, pp. 331-334

[16] Seo, J. and Bai, D., (2004), An optimal maintenance policy for a system under periodic overhaul, Mathematical and Computer Modelling: issue 39 , pp. 373-380

[17] Srivastava, P.W. and Jain, N., (2011), Bayesian prediction of the overhaul effect on a repairable system with bounded failure intensity, Journal of Quality, Statistics and Reliability Engineering: vol. 2011

[18] Sharma, A., Yadava, G.S. and Deshmukh, S.G., (2011), A literature review and future perspectives on maintenance optimization, Journal of Quality in Maintenance Engineering: issue 17, pp. 5-25

[19] OLF 070, (2004), Application of IEC 61508 and IEC 61511 in the Norwegian Petroleum Industry

[20] Mishra, R.C., (2007), Reliability and Maintenance Engineering, New Age International Ltd., New Delhi

[21] Plucknette, D., (2014), Why are people afraid of RCM? [Online] Available from: http://www.maintworld.com/Asset-Management/Whyare-people-AFRAID-OF-RCM [Accessed: 24th July 2014]

[22] Liyanage, J., (2008), Integrated eOperations - eMaintenance: Applications in North Sea offshore assets. In Kobbacy, K.A.H. \& Murthy, D.N.P. (ed.), Complex System Maintenance Handbook (pp. 585-610). London: Springer-Verlag London Limited 